\title{
Sporadic hyperekplexia
}

INSERM

\section{Source}

INSERM. (1999). Orphanet: an online rare disease and orphan drug data base. Sporadic hyperekplexia. ORPHA:306776

A rare neurologic disease characterized by excessive startle response to unexpected auditory, tactile or visual stimuli, associated with hyperreflexia. 